ГРИШИНА Елена Евгеньевна - кандидат экономических наук, заведующий лабораторией Института социального анализа и прогнозирования Российской академии народного хозяйства и государственной службы при Президенте РФ (119034, Россия, г. Москва, Пречистенская наб., 11; grishina@ranepa.ru)

ЦАЦУРА Елена Алексеевна - кандидат социологических наук, старший научный сотрудник Института социального анализа и прогнозирования Российской академии народного хозяйства и государственной службы при Президенте РФ (119034, Россия, г. Москва, Пречистенская наб., 11; kovalenko-ea@ranepa.ru)

\title{
СОЦИАЛЬНОЕ ОБСЛУЖИВАНИЕ ПОЖИЛЫХ: ЧТО ПРОИСХОДИТ И ВОЗМОЖНО ЛИ РАЗВИТИЕ?
}

Аннотация. В статье анализируется текущая ситуация в сфере социального обслуживания пожилых в России. Происходящие изменения сравниваются с мировыми трендами развития систем долговременного ухода. Авторы отмечают, что усиление межведомственного взаимодействия между медицинскими учреждениями и учреждениями социального обслуживания, создание на федеральном уровне методических рекомендаций по оценке нуждаемости в обслуживании и системы поддержки ухаживающих родственников способствовали бы повышению доступности и качества обслуживания, а также улучшению качества жизни пожилых.

Ключевые слова: социальное обслуживание, социальные услуги, пожилые, старение, система долговременного ухода

$\mathrm{P}$ оссия, как и европейские страны, стоит перед лицом демографических вызовов, связанных с ростом продолжительности жизни и старением населения. Так, по данным Росстата, в 2050 г. в России на 100 лиц трудоспособного возраста будет приходиться более 74 чел. старше трудоспособного возраста (в 2017 г. - лишь 46 чел.) $)^{1}$. Для сравнения: в странах Европейского союза к 2050 г. на 100 чел. в возрасте от 15 до 64 лет будет приходиться более 50 чел. в возрасте от 65 лет и старше (в 2017 г. - лишь 30 чел.) $)^{2}$.

Озабоченность демографическими вызовами нашла отражение в стратегических документах. Распоряжением Правительства РФ № 164-р от 5 февраля 2016 г. принята Стратегия действий в интересах граждан старшего поколения в Российской Федерации до 2025 года, направленная на создание условий для активного долголетия граждан старшего возраста ${ }^{3}$. В указе Президента РФ от 07.05.2018 № 204 «О национальных целях и стратегических задачах развития Российской Федерации на период до 2024 года» отмечена необходимость разработки и реализации программы системной поддержки и повышения качества жизни граждан старшего поколения ${ }^{4}$.

Анализ данных обследования населения старшего возраста по вопросам соци-

\footnotetext{
1 Росстат. 2017. Демографический ежегодник России. 2017 г. Доступ: http://www.gks.ru/bgd/regl/ B17_16/Main.htm (проверено 05.06.2018).

2 Eurostat. 2018. Baseline projections: demographic balances and indicators. URL: http://ec.europa.eu/ eurostat/data/database (accessed 08.06.2018).

3 Распоряжение Правительства РФ № 164-р от 05.02.2016. Доступ: https://www.garant.ru/products/ ipo/prime/doc/71222816/ (проверено 05.05.2019).

4 Указ Президента РФ от 07.05.2018 № 204 «О национальных целях и стратегических задачах развития Российской Федерации на период до 2024 года». Доступ: https://www.garant.ru/products/ipo/ prime/doc/71837200/ (проверено 05.05.2019).
} 
ального обслуживания, проведенный ИНСАП РАНХиГС в 2017 г. ${ }^{1}$, показал, что практически вся нагрузка по уходу и помощи пожилым приходится на их родственников. Не более $10 \%$ респондентов в возрасте свыше 75 лет и лиц, оценивающих свое здоровье как очень плохое, пользуются услугами соцработника. Среди лиц, испытывающих, по их словам, серьезные проблемы с осуществлением повседневной бытовой деятельности, охват услугами социального работника не превышает 20\%. При этом 35-40\% респондентов с очень плохим здоровьем или неспособные самостоятельно совершать покупки или справляться с работой дому заявили, что нуждаются в социальных услугах, прежде всего в помощи в быту. Все это делает актуальным вопрос о состоянии сферы социального обслуживания в России и перспективах ее развития.

\section{Цели и методология исследования}

Цель нашего исследования состоит в анализе состояния системы социального обслуживания пожилых граждан в России. В статье рассмотрены следующие исследовательские вопросы. Какие ключевые изменения произошли после 2013 г. в сфере социального обслуживания пожилых граждан? Какие основные тенденции, характеризующие состояние системы социального обслуживания пожилых людей, можно выделить? Какие ключевые проблемы мешают развитию системы социального обслуживания и системы долговременного ухода в частности? Кроме того, ситуация в России сравнивается с основными мировыми трендами в сфере социального обслуживания и долговременного ухода.

В качестве источников данных для анализа были использованы статистические формы собес № 3 и № 6 Росстата за 2012-2016 гг., дорожные карты регионов «Повышение эффективности и качества услуг в сфере социального обслуживания населения (2013-2018 годы)», а также интервью в 6 регионах ${ }^{2}$ с представителями руководящего звена органов исполнительной власти, учреждений социального обслуживания и фокус-группы с социальными работниками.

\section{Теоретический контекст исследования}

В мировой научной литературе целое направление исследований посвящено вопросу распределения ответственности за уход между человеком, семьей, государством и рынком. Исходя из различных параметров, характеризующих сложившиеся системы социального обслуживания и ухода в разных странах, исследователи создают типологии для межстранового сравнения. Например, Поммер и соавторы отмечают, что основная ответственность за удовлетворение потребностей в уходе может лежать на человеке (скандинавская модель), нуклеарной семье (континентальная модель) или расширенной семье (средиземноморская модель). И там, где меньше ответственность семьи, сильнее участие государства [Pommer, Woittiez, Stevens 2007]. ВОЗ предлагает типологизировать системы долговременного ухода в зависимости от решения организационных вопросов: адресность или универсальность доступа к системе; основной источник финансирования - налоги или страхование; жесткость проверки доходов и других критериев определения нуждаемости; объемы обслуживания; наличие денежных пособий ${ }^{3}$. В типологию может быть добавлена информация, например, о предоставлении и потреблении государственного и негосударственного

\footnotetext{
1 Телефонный опрос лиц, имеющих звание «Ветеран труда», проведенный в мае 2017 г. Случайная систематическая стратифицированная двухосновная выборка номеров мобильных и стационарных телефонов. Размер выборки - 1890 чел.

2 Тверская, Рязанская, Калининградская, Кемеровская, Омская, Тульская обл.

3 WHO. 2003. Key Policy Issues in Long-Term Care. World Health Organization Collection on Long-Term Care. 270 p.
} 
обслуживания, статусах здоровья, семейных связях [Pommer, Woittiez, Stevens 2007].

При межстрановых сравнениях описываются как общие проблемы (финансирование, качество обслуживания, определение нуждаемости, адресность или универсальность, потребительский выбор и т.д.) [Munday 2000; Kiersey, Coleman 2017], так и особенности ситуации в отдельных странах [Damiani et al. 2011].

Анализ современных моделей социальной политики в различных странах развитого мира показывает, что в настоящее время четкого водораздела между каноническими моделями уже не существует. Большинство европейских стран постепенно перестали придерживаться одной социальной модели и комбинируют различные подходы с учетом специфики страны (адресность, социальное страхование и субсидиарность, всеобщие гарантии минимального дохода и доступности основных услуг). Например, Ранчи и Паволини отмечают, что за последние несколько лет страны, в которых системы ухода были менее развиты, расширили охват и объемы обслуживания, т.е. шли по пути универсализации, а страны с универсалистскими моделями, напротив, вводят определенные ограничения [Ranci, Pavolini 2015]. В целом развитие систем социального обслуживания в Европе с конца XX в. во многом происходит под влиянием идеологии нового государственного управления (New Public Management), предполагающей внедрение рыночных принципов, конкуренции для повышения бюджетной эффективности государственных услуг.

Настоящая работа дополняет картину данными о российской системе социального обслуживания, затрагивая и сравнение с общеевропейскими тенденциями. В постсоветский период система социальной политики уходит от социально-демократической модели в сторону либеральной модели [Григорьева 2017; Романов, Ярская-Смирнова 2002]. Однако ряд унаследованных черт, например, забюрократизированность и достаточно высокие запросы к государству со стороны населения, мешают процессу адаптации к новым рыночным условиям [Салмина 2015].

Принятие нового закона о социальном обслуживании (442-Ф3 от 28.12.2003) и «майские указы» Президента РФ (2012 г.) обозначили новый этап развития системы социального обслуживания населения, в т.ч. пожилых граждан. Новое законодательство изменило рамки платного и бесплатного обслуживания, регламентировало расширение сети поставщиков социальных услуг за счет негосударственных участников. «Майские указы» существенно повысили размер оплаты труда социальных работников и медицинского персонала, повлияли на изменение нагрузки на персонал.

В целом, попытки вписать российскую систему в имеющиеся типологии систем социального обслуживания, как правило, говорят о близости к моделям, характерным для восточноевропейских стран, со стремлением минимизировать социальные расходы. Однако такие сопутствующие характеристики, как повышение качества услуг, развитие мониторинга эффективности работы, в России пока находятся на начальном уровне [Grigoryeva, Pervova, Smirnova 2015].

\section{Текущая ситуация в сфере социального обслуживания пожилых}

Анализ ведомственной статистики (формы собес № 3 и № 6) позволяет описать текущую ситуацию и выявить основные проблемные места. В связи с тем, что за последние 5 лет экономическая ситуация претерпела существенные изменения, анализ текущей ситуации представляет особый интерес и новизну. На конец 2016 г. в организациях, осуществляющих стационарное обслуживание граждан пожилого возраста и инвалидов, проживали 253 тыс. чел. За 2016 г. отделения временного и дневного проживания обслужили соответственно 20,5 
и 196,9 тыс. чел., а на надомном обслуживании на 1 января 2017 г. состояли 1138 тыс. чел.

Надомное обслуживание является основным видом обслуживания - доля лиц, обслуживаемых на дому, составляет $89 \%$ среди лиц старше трудоспособного возраста, обслуживаемых на дому и в стационарных учреждениях социального обслуживания.

В целом, охват пожилых услугами системы социального обслуживания очень низкий. Причем за последние 5 лет охват снизился. Доля лиц старше трудоспособного возраста, получающих услуги социального обслуживания на дому и в стационере, в общей численности лиц старше трудоспособного возраста составляет 3,3\%. Другие формы обслуживания - специализированные отделения социально-медицинского обслуживания на дому, полустационарное обслуживание, отделения временного проживания и социально-реабилитационная служба - действуют только в некоторых регионах и охватывают в совокупности не более $2,5 \%$ численности лиц старше трудоспособного возраста.

Кроме того, данные статистического наблюдения свидетельствуют о сокращении разнообразия форм социального обслуживания в регионах. Численность регионов, в которых присутствуют специализированные отделения социальномедицинского обслуживания на дому, сократилась в период с 1 января 2013 г. по 1 января 2017 г. более чем в 1,8 раза - с 59 до 32 регионов. При этом в регионах, в которых данные отделения продолжили действовать, нагрузка на одного социального работника существенно возросла. В период с 1 января 2013 г. по 1 января 2017 г. число регионов, в которых есть отделения временного проживания, сократилось с 43 до 36, а где есть отделения дневного пребывания - с 63 до 51.

В 2013 году в планах мероприятий (дорожные карты) «Повышение эффективности и качества услуг в сфере социального обслуживания населения (20132018 годы)» регионы сформулировали основные проблемы отрасли и поставили задачи для решения до 2018 г. $^{1}$ В частности, чаще всего региональные власти указывали на следующие пять проблем: неразвитый рынок негосударственных поставщиков; устаревшую материально-техническую базу; очередь; низкий уровень оплаты труда социальных работников; слабое развитие стационарозамещающих технологий. В 2018 г. можно подвести итоги и сделать выводы о том, смогли ли регионы решить указанные проблемы.

Анализ дорожных карт и ведомственной статистики (формы собес № 3 и № 6) показывает, что 2 задачи сохраняют высокую актуальность: развитие рынка негосударственных поставщиков и развитие стационарозамещающих технологий. Данные свидетельствуют, что регионы находятся только в самом начале пути развития рынка негосударственных поставщиков услуг. Так, несмотря на положительную динамику появления негосударственных поставщиков и рост числа обслуженных ими, численность лиц, обслуженных за год социальными службами, основанными на иных формах собственности, очень низкая и составляет на 1 января 2017 г. в целом по Российской Федерации лишь 7,2 чел. на 10 тыс. чел. населения. Среди основных барьеров развития рынка негосударственных поставщиков услуг исследователи называют неразвитость конкурентной среды, коррупционные составляющие при аутсорсинге социальных услуг, отсутствие необходимых стандартов социальных услуг, оценки/ контроля социальных услуг, неадекватное финансирование оказания социаль-

\footnotetext{
1 Были проанализированы дорожные карты «Повышение эффективности и качества услуг в сфере социального обслуживания населения (2013-2018 годы)» 74 регионов, которые присутствуют в базе нормативных документов «Региональный Консультант».
} 
ных услуг, нехватку профессиональных кадров, состояние спроса на рынке 1 [Еферина, Лизунова, Просянюк 2015]. Об этих проблемах сообщали и руководители учреждений и органов управления социальным обслуживанием в регионах в ходе интервью.

В субъектах РФ происходит внедрение различных видов стационарозамещающих технологий: мобильные бригады, приемная семья для пожилых, стационар на дому, социальное такси, сиделки, санаторий на дому, бригадный метод, «тревожная кнопка» и др. В то же время охват многими из перечисленных технологий лиц старшего возраста, проживающих в регионах, зачастую крайне низок. Технологии внедряются в отдельных районах на уровне пилотных учреждений.

Остальные задачи формально были достаточно успешно решены за прошедший период. Укрепление материально-технической базы является важным позитивным изменением, происшедшим в сфере социального обслуживания населения в последние несколько лет. Произошло существенное сокращение числа зданий стационарных учреждений социального обслуживания населения, требующих реконструкции (в 3,7 раза в период с 1 января 2013 г. по 1 января 2017 г.), находящихся в аварийном состоянии (в 5,2 раза), а также находящихся в ветхом состоянии (в 3,4 раза). Судя по дорожным картам, именно на ремонтные работы было направлено основное финансирование. Только в 9 регионах упоминалась необходимость обновления или закупки оборудования. И даже среди них некоторые регионы поясняют, что речь идет не только о реабилитационном или медицинском оборудовании для получателей услуг, но об оборудовании для столовых или прачечных.

Очередь на принятие на надомное обслуживание невелика. Более того, в период с 1 января 2013 г. по 1 января 2017 г. очередь сократилась в 14 раз и составляет менее тысячи человек (896 чел. на 1 января 2017 г.) по всей стране. Очередь для принятия на обслуживание специализированными отделениями социально-медицинского обслуживания на дому на 1 января 2017 г. составляла в целом по Российской Федерации лишь 238 чел. Правда, пока сохраняется очередь на стационарное обслуживание - 9166 чел. (из них 996 чел. - в Московской обл.). Сочетание столь низкого охвата обслуживанием и явной потребностью пожилых граждан в услугах вызывает вопрос, почему востребованность системы социального обслуживания настолько мала? Населению нужны другие услуги? Или дело в том, как формируется очередь? Респонденты отмечали, что процесс оценки нуждаемости в настоящее время очень субъективен и не отражает реальных потребностей пожилых людей. В некоторых регионах осуществляется закупка стационарных услуг у негосударственных поставщиков.

Повышение уровня оплаты труда социальных работников государственных организаций социального обслуживания до средней заработной платы по региону было одной из задач «майских указов» президента России 2012 г. В 2017 г. отношение средней заработной платы социальных работников к среднемесячному доходу от трудовой деятельности по субъектам РФ составило в среднем по России 74\% (в 20 регионах она составляла менее $80 \%$, в 65 регионах - от $80 \%$ до $89 \%$ и в 2 регионах превышала 90\%). В январе-марте 2018 г. отношение средней заработной платы социальных работников к оценке среднемесячной начисленной заработной платы наемных работников в организациях, у индивидуальных предпринимателей и физических лиц составило в среднем по России $89,9 \%$ и в большинстве регионов (в 76 регионах) превысило 100\%. При этом параллельно с увеличением заработной платы в период с 1 января 2013 г. по

\footnotetext{
1 Перспективы НКО в качестве поставщиков общественной пользы. - Исследовательская группа ЦИРКОН. 2013. 88 с. Доступ: http://www.zircon.ru/upload/iblock/d5d/Perspektivy_NKO_v_kachestve_ postavshhikov_obshhestvennoj_polzy.pdf (проверено 05.05.2019).
} 
1 января 2017 г. нагрузка на одного социального работника увеличилась в 1,3 раза и в среднем по Российской Федерации составила 8,4 чел., обслуживаемых на дому. Кроме того, численность социальных работников в центрах социального обслуживания в указанный период сократилась на 16\%. Значимой проблемой является существенное сокращение разрыва в заработной плате высококвалифицированных специалистов и специалистов со средним профессиональным образованием (или даже без образования) в связи с реализацией «майских указов» президента РФ 2012 г., что отрицательно сказывается на мотивации высококвалифицированных специалистов. Заработная плата в сфере социального обслуживания является низкой и поэтому непривлекательной для специалистов высокого уровня квалификации со специализацией в области управления, юриспруденции и психологии.

\section{Ситуация в России в контексте мировых трендов}

Рассмотрим ситуацию в России в контексте основных мировых трендов в сфере социального обслуживания пожилых. В настоящее время зарубежные страны используют различные системы определения нуждаемости лиц старшего возраста в услугах длительного ухода. Как правило, стандартизированная процедура оценки нуждаемости разрабатывается на национальном уровне и формируется с учетом структуры действующей системы поддержки пожилых, бюджетных возможностей и сложившихся в обществе представлений о социальной справедливости [Muir 2017]. В то же время в России признание человека нуждающимся в социальном обслуживании происходит достаточно субъективно, на федеральном уровне не установлен механизм оценки нуждаемости в социальном обслуживании со спецификацией форм и видов оказываемых услуг в зависимости от характеристик нуждаемости. Четкие объективные критерии оценки нуждаемости и прозрачная регламентация позволили бы избежать необъективного подхода в предоставлении социальной поддержки.

Предотвращение ухудшения состояния человека и расширения его нужд становится приоритетом в работе системы социальной поддержки развитых стран. Передовой опыт социального обслуживания пожилых связан с применением технологий максимально возможного возврата активности или сохранения возможности справляться самостоятельно с большинством повседневных дел. Это позволяет как повысить качество жизни человека, так и не допустить рост расходов на более интенсивную поддержку. В России пока такие технологии и подходы только планируются. Для этого необходимо повышение кадровой обеспеченности учреждений социального обслуживания и проведение масштабного обучения кадров. В целом, система социального обслуживания на дому настроена на обслуживание «пассивных» получателей услуг без качественного изменения социального статуса человека, законодательство не предусматривает механизмы повышения активности получателей услуг [Парфенова 2017].

Несмотря на то что большинство получателей социального обслуживания проживают дома, в России только начинается движение в сторону деинституционализации взрослых, нуждающихся в социальном обслуживании. При этом пока речь не идет о том, чтобы переводить людей, обслуживающихся в стационарных учреждениях, на другие формы, но лишь о том, чтобы по возможности сохранить проживание дома. Мировой тренд состоит в том, чтобы обслуживание осуществлялось на дому и поблизости от места проживания, максимально сохранялась независимость и самостоятельность получателей услуг. Важное значение придается развитию механизмов координации помощи, социальному сопровождению (кейс-менеджмент). 
Развитие системы долговременного ухода невозможно без сближения систем здравоохранения и социального обслуживания. В России пока взаимодействие между двумя секторами налажено недостаточно, существуют серьезные пробелы. Так, например, не налажена координация мероприятий в рамках пилотного проекта по развитию системы долговременного ухода за пожилыми, реализуемого Министерством труда и социальной защиты, и пилотного проекта «Территория заботы», направленного на организацию долговременной медицинской и социальной помощи гражданам пожилого и старческого возраста и осуществляемого под контролем Министерства здравоохранения РФ. Взаимодействие между учреждениями социального обслуживания и здравоохранения зачастую не закреплено соответствующими соглашениями на уровне субъектов РФ или закреплено формально и во многом зависит от личных усилий руководителей учреждений. В то же время мировой опыт содержит целый набор моделей объединения усилий двух секторов для более эффективной помощи нуждающимся пожилым и инвалидам - объединение администрирования, размещение услуг разных поставщиков в одном месте, создание сетевого партнерства между отдельными учреждениями здравоохранения и социального обслуживания, кейс-менеджмент (социальное сопровождение), создание цепочек обслуживания [Brodsky, Habib, Hirschfeld 2003]. В России можно наблюдать обратный процесс - вывод медицинского персонала за штат стационарного учреждения социального обслуживания. Это негативно оценивается руководителями данных учреждений, поскольку может привести к снижению доступности медицинских услуг и, соответственно, ухудшению качества жизни обслуживаемых. Достаточно остро для пожилых лиц, состоящих на надомном обслуживании, стоит проблема получения медицинских услуг узких специалистов (например, окулиста, отоларинголога, хирурга, кардиолога и др.). Кроме того, налаживание межведомственного взаимодействия между учреждениями социального обслуживания и учреждениями здравоохранения крайне необходимо для упрощения процедуры оформления направления нуждающихся пожилых лиц на стационарное социальное обслуживание.

В России мониторинг результатов социального обслуживания сосредоточен на показателях числа обслуженных, объема предоставленных услуг и других показателях процесса. Передовой опыт смещает фокус внимания на конечные результаты для получателей услуг и показатели изменения качества их жизни в результате получения социального обслуживания или предоставления поддержки родственникам, осуществляющим уход. Существует проблема формирования объективных и измеримых показателей, оценивающих качество социального обслуживания. Традиционно используемые показатели объема услуг, численности обслуживаемых и удовлетворенности получателей услуг не могут в полной мере оценить, насколько изменилось качество социального обслуживания и качество жизни пожилых [Makai et al. 2014; Rand et al. 2017].

Мировой опыт представляет множество форм поддержки тех, кто ухаживает за близкими людьми. Уход за родственником оказывает серьезный негативный эффект на членов семьи. Ситуация усугубляется с ростом объемов предоставляемой поддержки родственникам, и критическая точка -20 часов ухода в неделю и больше [Carmichael, Charles 1998; Colombo et al. 2011]. Для снижения негативного эффекта и обеспечения более качественного и длительного ухода родственниками дома мировой опыт предлагает следующие механизмы поддержки родственников, осуществляющих уход: финансовая поддержка (различные пособия), инструменты сохранения занятости на рынке труда (отпуск по уходу, гибкие рабочие часы), обеспечение пенсионных прав, забота о благополучии родственников (программы передышки, консультирования 
и обучения) ${ }^{1}$ [Colombo et al. 2011]. Поддержка родственников выгодна государству, т.к. снижает негативные последствия для домохозяйства и позволяет родственникам дольше ухаживать за своими близкими, а человеку - стареть и жить дома до конца. В России поддержка родственников не является приоритетом и не является задачей системы социального обслуживания. За последние годы в некоторых регионах появились школы обучения уходу, и, пожалуй, это единственная мера, направленная на поддержку тех, кто сталкивается с необходимостью за кем-то ухаживать. В отдельных регионах (например, в Москве, Томской, Тюменской, Калининградской обл. и ряде других регионов) есть опыт организации дневного пребывания лиц старше трудоспособного возраста в так называемых детских садах для пожилых, однако в целом по России охват лиц старшего возраста такими технологиями является крайне низким.

\section{Выводы}

Государственная система социального обслуживания пожилых граждан очень инерционна, и при этом на нее действуют две разнонаправленных тенденции. С одной стороны, идет стимулирование внедрения инновационных стационарозамещающих технологий, развитие системы долговременного ухода в целом, развитие рынка поставщиков социальных услуг. С другой стороны, экономические реалии последних лет приводят к сокращению штатов, направлений работы, росту нагрузки на персонал, отсутствию ресурсов для прорывной работы. Государственные ресурсы были направлены на укрепление материально-технической базы - реконструкцию и ремонт зданий.

Охват пожилых различными формами социального обслуживания за последние 5 лет сократился в несколько раз. Основные формы - надомное и стационарное социальное обслуживание - на 1 января 2017 г. охватывали лишь $3,3 \%$ лиц старше трудоспособного возраста. Парадокс заключается в том, что при росте числа пожилых граждан в составе населения и снижении охвата очередь на надомное обслуживание за последние 5 лет сократилась в 14 раз и фактически ликвидирована (менее 1000 человек на всю страну).

Достигнутые успехи в укреплении материально-технической базы, повышении уровня оплаты труда социальных работников и сокращение очереди на социальное обслуживание вызывают ряд непростых вопросов. Так, было ли достигнуто укрепление материально-технической базы не только в состоянии зданий, но и в оснащении учреждений, наполненности необходимым реабилитационным и абилитационным оборудованием и средствами ухода? Применение каких механизмов позволило обеспечить столь резкое сокращение очереди? Если произошло снижение востребованности услуг, то почему? Повышение заработной платы социальных работников практически повсеместно сопровождалось достаточно сильным ростом нагрузки. Во многих регионах произошло сокращение штатов социальных работников. Как это сказалось на качестве и объемах предоставляемых услуг? Данные вопросы требуют дальнейшего исследования.

Очевидно, что практически полностью уход за пожилыми и их поддержка это забота родственников. Государство при этом не уделяет должного внимания поддержке тех, кто ухаживает за близкими. Хорошо, что начинают появляться школы обучения навыкам ухода, однако мировой опыт показывает, что поддержка родственников должна быть более комплексной (поддержка материаль-

1 European Experiences with Long-Term Care: France, the Netherlands, Norway, and the United Kingdom. AARP European Leadership Study. 2006. 35 p. 
ного положения, занятости, здоровья, предоставление возможности отдохнуть и восстановить силы, обеспечение пенсионных прав).

Демографические вызовы, связанные с ростом продолжительности жизни и старением населения, повышают актуальность реформирования системы социального обслуживания лиц старшего возраста. Мировой опыт показывает, что для развития системы социального обслуживания необходимы структурные изменения в системе социального обслуживания: деинституционализация; перемещение фокуса на максимально возможное сохранение независимости и самостоятельности получателей услуг; расширение рынка поставщиков за счет привлечения некоммерческих и коммерческих организаций к оказанию услуг; введение обязательных или добровольных систем менеджмента качества услуг; ориентация на потребности клиентов, качество жизни и конечные результаты для получателей услуг; сближение здравоохранения и социального обслуживания; развитие механизмов координации помощи, а также развитие комплексной поддержки тех, кто ухаживает за родственниками и друзьями. Данные изменения способствовали бы повышению доступности и качества социального обслуживания и улучшению жизни лиц старшего возраста.

\section{Список литературы}

Григорьева И. 2017. Сто лет трансформаций социальной политики в России. - Журнал исследований социальной политики. № 15(4). С. 497-514.

Еферина Т.В., Лизунова В.О., Просянюк Д.В. 2015. Механизмы повышения качества социальных услуг: разгосударствление сферы социального обслуживания населения. Доступ: http://ac.gov.ru/files/content/1828/statya-eferina-lizunovaprosyanyuk-2-red-pdf.pdf (проверено 05.05.2019).

Парфенова О. 2017. Социальные сервисы для пожилых: формальные и неформальные правила и практики. - Журнал исследований социальной политики. Т. 15. № 4. С. 573-588.

Романов П., Ярская-Смирнова Е. 2002. Социальная политика и социальная работа в изменяющейся России. М.: Изд-во ИНИОН РАН. 456 с.

Салмина А.А. 2015. Установки населения по отношению к социальной роли государства в России и Германии. - Власть. № 1. С. 171-181.

Brodsky J., Habib J., Hirschfeld M. 2003. Key Policy Issues in Long-term Care. Geneva: World Health Organization. 281 p.

Carmichael F., Charles S. 1998. The Labour Market Costs of Community Care. Journal of Health Economics. Vol. No. 6. 17. P. 747-765.

Colombo F., Llena-Nozal A., Mercier J., Tjadens F. 2011. Help Wanted? Providing and Paying for Long-term Care. Paris: OECD Health Policy Studies: OECD Publishing. $324 \mathrm{p}$.

Damiani G., Farelli V., Anselmi A., Sicuro L., Solipaca A., Burgio Al., Iezzi D.F., Ricciardiet W. 2011. An evidence review. Patterns of Long Term Care in 29 European Countries: Evidence from an Exploratory Study. - BMC Health Services Research. Vol. 11. P. 316-324.

Grigoryeva I., Pervova I., Smirnova A. 2015. Inequalities in Eligibility for Social Care: An International Context. - Журнал исследований социальной политики. № 2. C. 317-330.

Kiersey R., Coleman A. 2017. Approaches to the Regulation and Financing of Home Care Services in Four European Countries. Dublin: Health Research Board. 112 p.

Makai P., Brouwer W., Koopmanschap M., Stolk E., Nieboer A.P. 2014. Quality of Life Instruments for Economic Evaluations in Health and Social Care for Older People: a systematic review. - Social Science and Medicine. Vol. 102. P. 83-93. 
Munday B. 2000. European Social Services: A Map of Characteristics and Trends. Anheier. $21 \mathrm{p}$.

Muir T. 2017. Measuring Social Protection for Long-term Care. - OECD Health Working Papers. No. 93. Paris: OECD Publishing. 57 p.

Pommer E., Woittiez I., Stevens J. 2007. Comparing Care. The care of the elderly in ten EU-countries. The Netherlands Institute for Social Research (SCP). 42 p.

Ranci C., Pavolini E. 2015. Not All that Glitters Is Gold: Long-term Care Reforms in the Last Two Decades in Europe. - Journal of European Social Policy. Vol. 25. No. 3. P. 270-285.

Rand S., Caiels J., Collins G., Forder J. 2017. Developing a Proxy Version of the Adult Social Care Outcome Toolkit (ASCOT). - Health and Quality of Life Outcomes. Vol. 15. No. 1. P. 108-121.

GRISHINA Elena Evgen'evna, Cand.Sci. (Econ.), Head of the Laboratory of the Institute for Social Analysis and Prediction, RANEPA (11 Prechistenskaya Emb, Moscow, Russia, 119034; grishina@ranepa.ru)

TSATSURA Elena Alekseevna, Cand.Sci. (Soc.), Senior Researcher of the Institute for Social Analysis and Prediction, RANEPA(11 Prechistenskaya Emb, Moscow, Russia, 119034; kovalenko-ea@ranepa.ru)

\section{SOCIAL SERVICE FOR THE ELDERLY: WHAT IS HAPPENING AND IS DEVELOPMENT POSSIBLE?}

Abstract. The authors analyze the current situation in the social service system in Russia. Trends in the main indicators for social services for the elderly are analyzed based on the statistical forms of Rosstat for 2012-2016. Situation in social service system in Russia is compared with the modern trends in the system of long-term care. The article identifies that two divergent trends affect state social services. On the one hand, outpatient social care, long term care, social services market are developing. On the other hand, economic struggles of recent years have led to reduction of staff number and areas of work, the workload increase and the lack of resources for breakthrough. The authors note that the creation of a comprehensive system of support for relatives caring for elderly, the strengthening of cooperation between medical and social service institutions, the development of federal methodological recommendations for social services need assessment would improve the accessibility and quality of social services and improve the life quality of older persons.

Keywords: social care, social services, elderly, long-term care, aging 